\begin{tabular}{|c|c|}
\hline 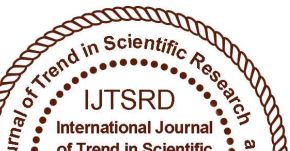 & $\begin{array}{l}\text { International Journal of Trend in Scientific } \\
\text { Research and Development (IJTSRD) }\end{array}$ \\
\hline 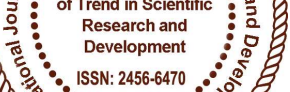 & International Open Access Journal \\
\hline 000 & ISSN No: 2456 - 6470 | www.ijtsrd.com | Volume - 2 | Issue - 3 \\
\hline
\end{tabular}

\title{
Study Impact of Nanotechnology on Human Social Welfare
}

\author{
Mrs. Zamzama Rahmany \\ PG. Scholar, Department of MSc Physic, University College of Sciences \\ Osmania University, Hyderabad, Telangana, India
}

\begin{abstract}
In this research study of nanotechnology is selected as the important point of discussion because Nanotechnology is the common word in this era, is rapidly progressing field, but many of us don't realize the amazing impact it has on our daily lives. scientists and engineers are having great success in making materials at the nanoscale to take advantages of enhanced properties such as higher strength, lighter weight, increased electrical conductivity, and chemical reactivity compared to their larger- scale equivalents. in this context, the paper outlines discuss the impact of nanotechnology on society, consist of the benefits that are experienced by every element of that on the society. the purpose of this systematic review is to seek to identify key scientific contribution that have been made by the nanotechnology effect to the present and future society.
\end{abstract}

Keywords: Nanotechnology, development, disadvantages, human life, society

\section{INTRODUCTION}

Nanotechnology is 'science, engineer and technology conducted at nanoscale, which is about 1 to 100 nanometer is a billionth of a meter (by United states national nanotechnology initiative 1999) .nanotechnology have achieved a lot of attention from the research people and also by general public. It is also so rapidly expanding field. The concept of nanotechnology was first discussed in 1959 by renowned physicist 'Richard Feynman' in his talk. 'there's plenty of room at the bottom', in which he described the possibility of synthesis via direct manipulation of atoms.

Nanotechnology term was first used by 'Norio Taniguchi' in 1974. inspired by Feynman's concept an engineer K.Eric Drexler, he wrote a book in 1986 'Engines Ir of Creation: The coming era of nanotechnology' and gave idea for its initiation. First, the invention of the scanning tunneling microscope in 1981- provided unprecedented visualization of individual atoms and bonds and was successfully used to manipulate individual atoms in 1986.Second, discovery of fullerenes in 1985 by Harry Kroto, Richard Smalley and Robert curl, who together own Noble prize 1996- suggested potential application for nanoscale electronics and devices.

Likewise the nanotechnology gets the fame in the society for research. The research in this field has made the practical implication of it possible. Now in 21 st century, we can observe that everything has some or other kind of dependency on nanotechnology. so every country is spending a huge amount of money for the advancement of this technology particularly in their country. 
Figure no.1- cross border funding of various countries in nanotechnological research

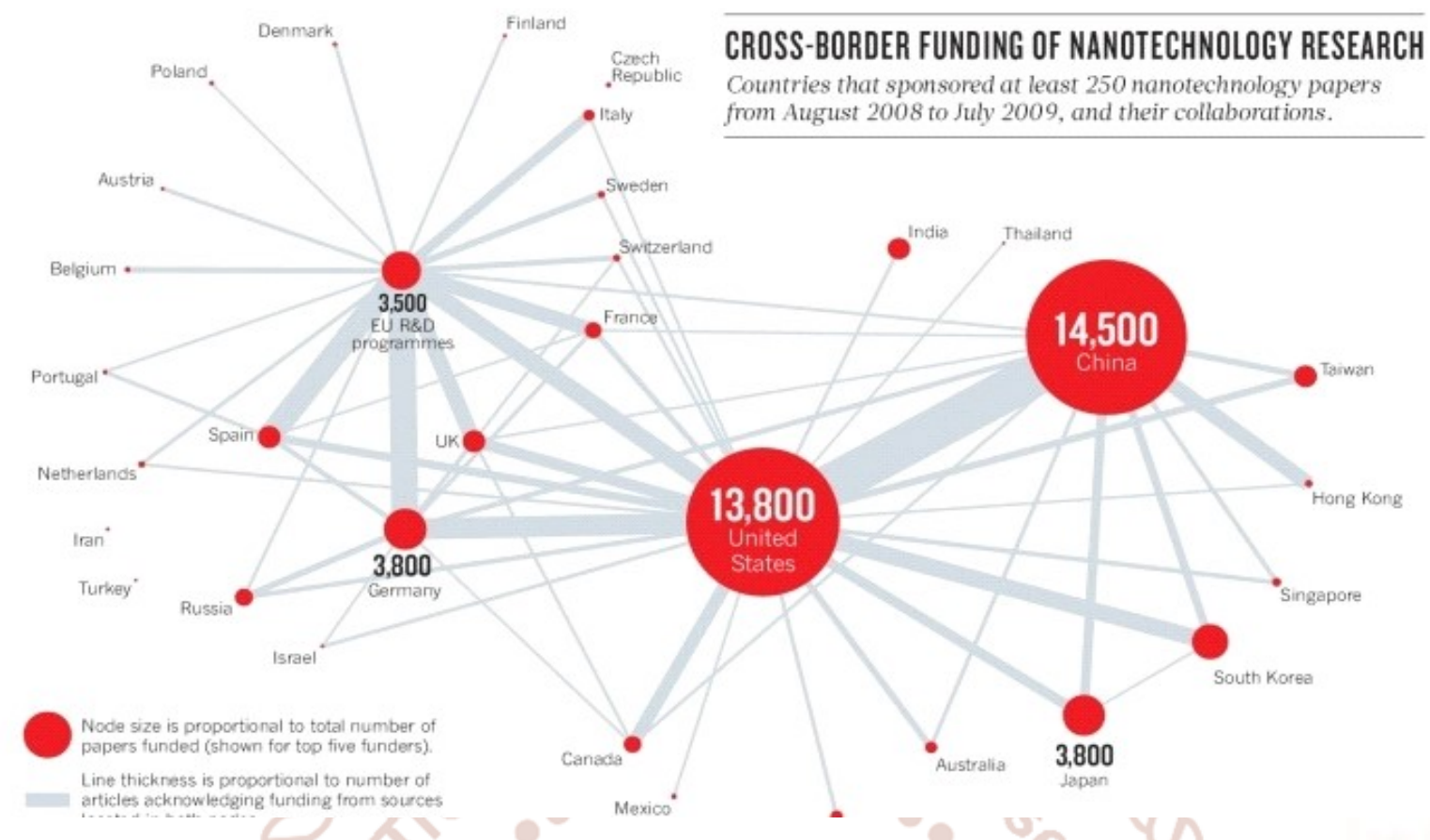

Figure no.1 is the graphical representation of cross linkage between the countries and their interdependency on each other, which says that it has its importance in all over the world but the advancement is dependent on the developmental speed of the country.

FIGURE NO. 2- ANNUAL NANOTECHNOLOGY FUNDING LEVELS

\section{Annual Nanotechnology Funding Levels}

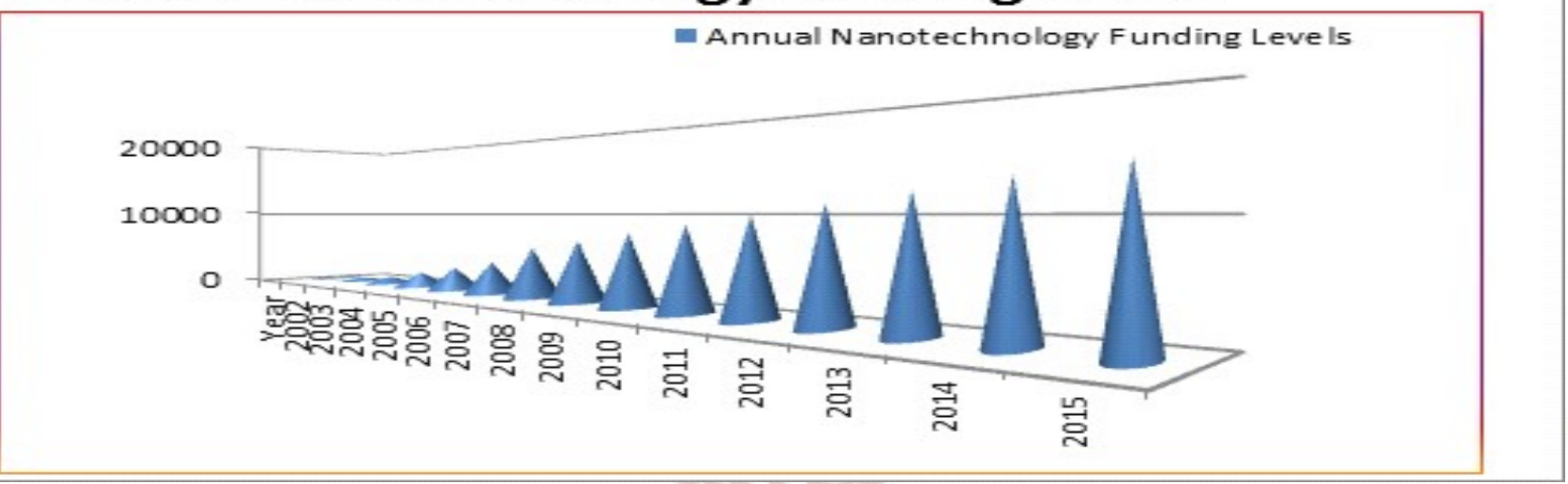

Figure no.2, shows the amount of funds being used year by year for the new advanced researches in nanotechnology.

Thus it can be concluded that now a days nanotechnology is the burning area for research and development. As we can see the advancement that is endulging in our life due to this technology, at the same time we are unable to recognize the bad effects of it. The loses that we are facing and the impact that will be there on the society.

\section{Review of Literature:}

- Nanotechnology is the science and technology of small things "in particular things that are less than $100 \mathrm{~nm}$ in size. For comparison, a human hair is about 60-80,000 nanometers wide. Scientists have discovered that materials at small dimensions "small particles, thin films, etc.- can have significantly different properties than the same materials at larger scale. There are thus endless possibilities for improved devices, structures, and materials if we can understand these differences, 
and learn how to control the assembly of small structures. Nanostructures--- objects with nanometer scale features-- are not new nor were they first created by man. There are many examples of nanostructures in nature in the way that plants and animals have evolved. Similarly there are many natural nanoscale materials $€_{\mid .}^{\prime}$. catalysts, porous materials, certain minerals, soot particles, etc. That has unique properties particularly because of the nanoscale features. What is new about nanotechnology is that we can now, at least partially, understand and control these structures and properties to make new functional materials and devices. We have entered the era of engineered nanomaterials and devices (NNINSeptember 2015).

- Nanotechnology is the construction and use of functional structures designed from atomic or molecular scale with at least one characteristic dimension measured in nanometers. Their size allows them to exhibit novel and significantly improved physical, chemical, and biological properties, phenomena, and processes because of their size. When characteristic structural features are intermediate between isolated atoms and bulk materials in the range of about one to 100 nanometers, the objects often display physical attributes substantially different from those displayed by either atoms or bulk materials. Phenomena at the nanometer scale are likely to be a completely new world. Properties of matter at nanoscale may not be as predictable as those observed at larger scales. Important changes in behavior are caused not only by continuous modification of characteristics with diminishing size, but also by the emergence of totally new phenomena such as quantum confinement, a typical example of which is that the color of light emitting from semiconductor nanoparticles depends on their sizes. Designed and controlled fabrication and integration of nanomaterials and nanodevices is likely to be revolutionary for science and technology. Nanotechnology can provide unprecedented understanding about materials and devices and is likely to impact many fields. By using structure at nanoscale as a tunable physical variable, we can greatly expand the range of performance of existing chemicals and materials. Alignment of linear molecules in an ordered array on a substrate surface (selfassembled monolayers) can function as a new generation of chemical and biological sensors. Switching devices and functional units at nanoscale can improve computer storage and operation capacity by a factor of a million. Entirely new biological sensors facilitate early diagnostics and disease prevention of cancers. Nanostructured ceramics and metals have greatly improved mechanical properties, both in ductility and strength (Zhong L Wang).

\section{Definition of Nanotechnology -}

- Nanotechnology is the term given to those areas of science and engineering where phenomena that take place at dimensions in the nanometer scale are utilized in the design, characterization, production and application of materials, structures, devices and systems. (European commission 2004).

- "Nanotechnology" is the science of manipulating materials on an atomic or molecular scale specially to build microscopic devices such as robots (Merriam Webster).

\section{METHODOLOGY:}

The descriptive research design is used to focus and to identify the impact and effective implementation of Nanotechnology in human life and dimension aspect of society.

\section{OBJECTIVES OF THIS RESEARCH}

1. - To know the influence of nanotechnology on the human life.

2. To know the dependency of human on the nanotechnology.

3. To know the harm effect of nanotechnology on the society.

\section{HYPOTHESIS}

1. Nanotechnology has advanced the living style of present generation.

2. 2. Nanotechnology has also brought problems to the society.

\section{CHARACTERISTICS OF NANOTECHNOLOGY}

- Nanotechnology is the engineering of functional systems at the molecular scale.

- Nanotechnology deals with putting things together atom by atom and with structures so small that they are invisible to the naked eye. It provides the 
ability to create materials, devices and systems with fundamentally new functions and properties.

- It has implications for almost every type of manufacturing process and product. Potential nanotechnology applications in the next few decades could produce huge amount of advancement in the society.

- Material reduced to the nanoscale can show different properties compared to what they exhibit on a macroscale, enabling unique application. example- The melting point drastically falls, possess high mechanical strength as compared to their conventional counterparts, etc.

\section{IMPACT OF NANOTECHNOLOGY}

Nanotechnology has enormous promises and some of them are achieved, that are called as positive aspects of nanotechnology.

\section{Positive Aspect:}

- Efficiency and environment friendlinessmolecular scale manufacturing ensures that very little raw material is wasted and that we make only what we intend to make, no more.

- Financial benefits for countries involved in itnanotechnology is expected to be a $\$ 2.6$ trillion market by 2015 . Each country involved, including Ireland, have a bright financial future ahead when it comes to gaining money with nanotechnology.

- Catalytic and remedial application- metal oxide Nano catalysts are being developed for the prevention of pollution due to industrial emission, e.g- DE NOx catalyst could be applied for the removal of nitrogen oxides from fossil file power plant emission gases, etc.

- Reduces the cost-Mass storage devices that can store more than a hundred billion bytes in a volume the size of a sugar cube, RAM that can store a mere billion billion bytes in such a volume and massively parallel computers of the same size that can deliver a billion instructions per second can be manufactured.

- Medical technology- would let us directly heal the injuries at the molecular and cellular level that are the root causes $\mathrm{f}$ disease and ill health which has not been possible up till now.

- Reduced the size and increased power- more powerful machines are build which consume less power and long lasting batteries.
- Improved pharmaceutical products- improved the absorption within the bosdy and make it easier to deliver, often through commination of medical devices.

- Improved vehicle fuel efficiency- made it lighter and more functional.

- Reduced the time usage- now things that would have taken days to complete now can be cone within some minutes or even seconds.

- Cosmetics- most of the sunscreens are made of nanotechnology that effectively absorbs sunlight, including dangerous UV rays.

- Security- sensors sre programmed which can detect a very small foreign particle, even CCTV cameras, etc are there for security purposes.

\section{Negative Aspect}

- Unemplyoment increases- since many new devices are being design which are capable of doing what humans can do, thus the job opportunities are decreasing day by day.

- Health- Nanoparticles have been shown to be absorbed in the livers of research animals and even cause brain damage in fish exposed to them after just 48 hours. If they can be taken up by cells, then they can enter our food chain through bacteria and pose a health threat like pesticides in vegetables or hormones in meat.

- High energy requirement- for synthesizing nanoparticles causing high energy demand.

- Lower recovery and recycling rate.

- Atomic weapons can now be more accessible and made to be more powerful and more destructive. These can also become more accessible with nanotechnology.

- Toxicity in environment- the toxic property of graphene is unknown, and is difficult to remove graphene from waste.

- Environmental- if nanomaterials really are as strong as diamonds, how decomposable or persistent are they? In the distant future, they will make self- replicating nanobots- necessary to create the trillions of Nano assemblers needed to build any kind of product- run amok, spreading as quickly as a virus, in the infamous "grey goo" scenario.

- Privacy- as the product shrink in size, eavesdropping devices too can become invisible to the naked eye and more mobile, making it easier to invade our privacy. Small enough to plant into our bodies, mind-controlling nanodevices may be able 
to affect our thoughts by manipulating brainprocess.

- Terrorism- capabilities of terrorists go hand in hand with the military advances, so as weapons become more powerful and portable, these devices can also be turned against us. Nanotech may create new, unimaginable forms of torture- disassembling a person at the molecular level or worse.
- Society- because nanotech laboratories can be small and mobile, surveillance needs to be practically everywhere- developing a free society into a big brother scenario. Also, what is the impact $\mathrm{n}$ the economy? If nations can make anything they want, will they lose all incentives to trade? What about morality- should we be playing with god-like powers?

\section{FIGURE NO. 3: RISKS AVAIL BY NANOTECHNOLOGY}

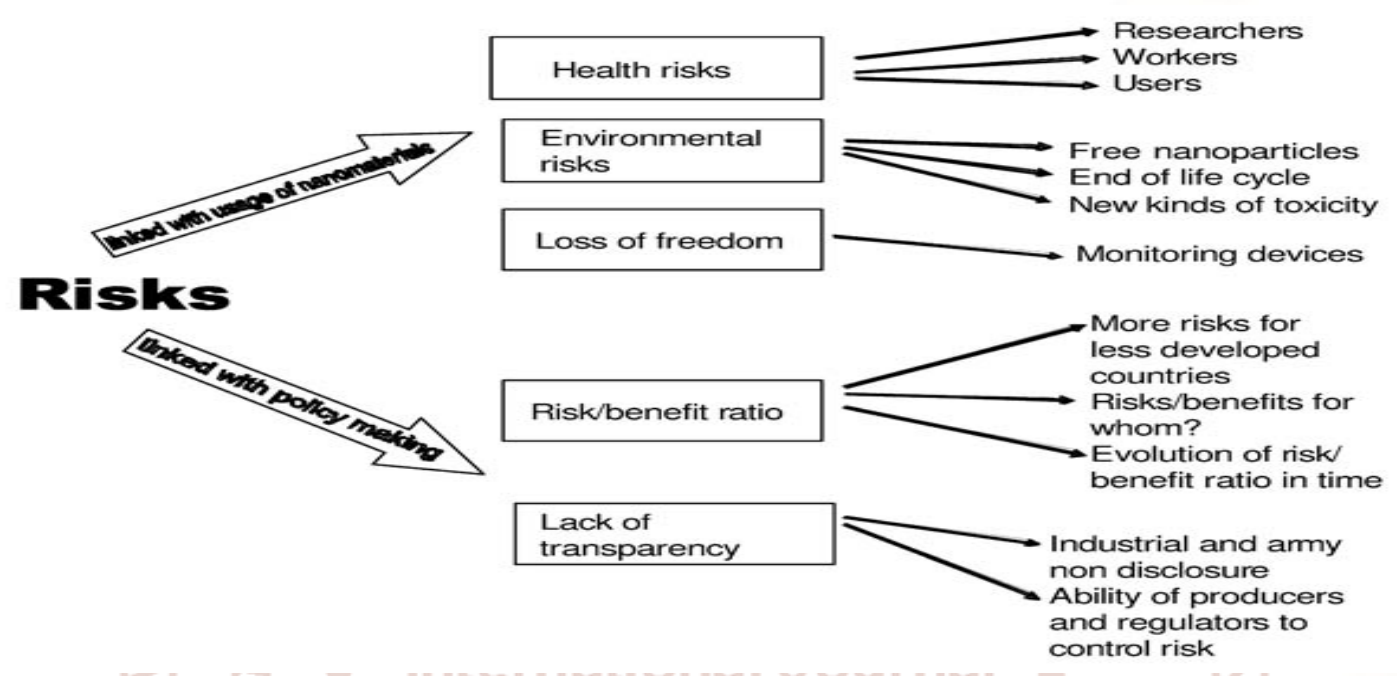

Figure no. 3- shows the risk we have because of nanotechnology.

\section{CONCLUSION}

There is a saying- good things come in small packages. Nanotechnology is certainly materialising this saying. It has become the new mantra of today's researches. It has the potential of making every manufactured product faster, lighter, stronger, smarter, safer and cleaner and even more precise. This manipulation of tiny elements will and can enable a host of new developments, including furniture that can think, cars that change colour, even mobile phones with breathalysers- which will warn us of excessive drinking.

It has its own benefits and harms. It serves both as blessing and curse. Now a day we can only see and observe the advantages provided by nanotechnology because they are dominating and There is no doubt about its impact on the flexibility and betterment of the society. But there is also no doubt that sonly we are going to feel the nanotechnology as curse and will see how they will damage the life span of the living beings. So as per our observation, the hypotheses made in the beginning are true.
So, the solution is only that if we want nanotechnology only as blessing, then use it in limit and only try to fulfil the need in spite of greed. Because needs can be satisfied at some stage but greed goes on with time and money.

\section{REFERENCES:}

1. 'Mind the gap': science and ethics in nanotechnology, Anisa Mnyusiwalla1,2,3, Abdallah S Daar1,2,3,4 and Peter A Singer1,2,3,5, Published 13 February 2003 - Nanotechnology, Volume 14, Number 3.

2. nanoscience.gatech.edu/zlwang/research

3. nanotechnologyforstudents.weebly.com/positiveand-negative-aspects

4. Essentials of nanotechnology by Jeremy Ramsden june, 2015.

5. An introduction to nanoparticle and nanotechnology by Maria Benelmekkiapril, 2015 